\title{
A consciência moral cristã e a neurociência
}

\section{Christian moral conscience and neuroscience}

Luiz Augusto de Mattos*

\begin{abstract}
RESUM0: Foram apresentados os desafios que a situação do ser humano atual tem diante de si para compreender a consciência psíquica e a consciência moral pelas mais diversas influências que sofrem. Assim, entre os diversos instrumentos disponíveis o autor dialoga com a neurociência. O desafio que se apresenta nos dias de hoje é compreender de modo crítico o que seja, afinal, a consciência psíquica e, ao mesmo tempo, que correspondência ela tem com a consciência moral - procurando analisar algumas questôes que surgem especialmente para a consciência moral.
\end{abstract}

PALAVRAS-CHAVE: Consciência. Moral. Neurociências.

ABSTRACT: This paper presents the challenges which the current condition of human beings has to face in order to understand psychic consciousness and moral conscience by considering the several different influences affecting them. This way, among the many available instruments, the author dialogues with neuroscience. The challenge that posits itself in the contemporary world consists in understanding from a critical point of view what is in the last analysis psychic consciousness, and, at the same time, what correspondence it could have to moral conscience - by examining some questions emerging specially for moral conscience.

KEYWORDS: Conscience. Moral. Neurosciences.

\section{INTRODUC̣̃̃O}

Uma temática que sempre foi muito importante e mais ainda na atualidade, quando se trata do campo da teologia moral, é a da consciência moral ${ }^{k}$, sobretudo diante dos grandes desafios que são enfrentados na atual civilização mundial. Nesse sentido, afirma-se que a consciência tornou-se questão central do nosso tempo. Horizontes alargados ressignificam conceitos, linguagens, práticas e atitudes. O fenômeno do pluralismo cultural, ideológico e religioso, a secularização, as novas antropologias, novos modelos de família, a biomedicina e a biogenética, o acesso irrestrito à informação, a consolidação da democracia e dos direitos humanos, a ampliação das opções morais, o sujeito pós-moderno e sua relativização das normas objetivas, a emancipação da sociedade e do cidadão do controle das religiōes, extrapolaram consideravelmente a noção da consciência como árbitro dos comportamentos vinculados à moral. A intimidade do indivíduo não está condicionada apenas pela religião. $\mathrm{O}$ acúmulo e aceleração das mudanças exigem esforço de escuta atenta das diferentes experiências, convicçóes e paradigmas. Os impasses éticos desafiam não apenas a consciência cristã, mas a consciência de toda a humanidade (p. 345) ${ }^{3}$.

Enfim, há que compreender que toda consciência está suscetível e sensível às mudanças que ocorrem na sociedade.

Pensar um compromisso humanitário na autonomia, na liberdade, na verdade, no amor e na responsabilidade implica a vivência de uma consciência adulta e cristã. O que existe de documentos, catálogos de normas, diretrizes de vida, códigos disciplinares, Direito Canônico e normas catequéticas tem significado maior quando está em função de uma experiência de consci-

DOI: $10.15343 / 1981-8254.20140801031045$

\# Uma versão simplificada do texto foi publicada em "Mattos LA. Revista Espaços. 2013;21(1):5-33".

* Doutor em Ética Teológica pela Faculdade N. S. da Assunção, São Paulo-SP, Brasil. Professor da Universidade São Francisco, São Paulo-SP, Brasil. Professor do ITESP, São Paulo-SP, Brasil. E-mail: escampelo88@yahoo.com.br

a. A consciência é definida como "o juízo ou o ditame prático da razão, com o qual julgamos o que aqui e agora deve ser feito porque bom ou deve ser evitado porque mau" (p. 102) ${ }^{1}$. Ademais, antes de falarmos de consciência cristấ, vamos procurar compreender o que entender por consciência e por consciência moral. Afirma Paul Valadier: "Tratar da consciência moral consiste, na realidade, em abordar a própria natureza da vida moral em seu ponto central: a decisão, ou seja, a escolha que uma pessoa faz de se engajar em um ato que ela assume, de maneira a poder prestar contas diante de si mesma e diante do outro, e diante de Deus, caso se trate de uma pessoa crente. Escolha precária, sempre arriscada e difícil, é assim porque através da questão da consciência é abordado também um problema antropológico importante. O que será deste ser, o homem, não inteiramente programado em sua conduta, condicionado de múltiplas maneiras, mas de tal forma que, sobre a base desses vários condicionamentos, inevitavelmente lhe é imposta a necessidade de optar entre possibilidades e, então, escolher a que lhe parece a mais sensata, ou a menos perigosa? O que será desse ser entregue a si mesmo e deixado com o encargo de decidir sobre sua vida, a vida dos outros, a sua relação com o mundo? Onde ele encontrará as referências necessárias para tais opçōes, se nele mesmo os instintos não o programam em oposição aos belos e vãos sonhos naturalistas, e se fora dele a multiplicidade das normas e das autoridades torna inútil um conformismo com a obediência e o continuísmo tranquilo?" (p. 15) ${ }^{2}$. $\mathrm{O}$ autor declara não haver conflitos de interesse. 
ência ética e responsável diante dos compromissos com a vida da humanidade ${ }^{b}$. Manter uma consciência lúcida e livre é fundamental para não esclerosar as próprias açôes, as quais deverão afugentar qualquer sintoma de rigorismo, fixismo, legalismo e autoritarismo. Há que afirmar que, desde que não esteja em perigo o depósito da fé, nem toda transgressão, à luz da consciência, é condenável ${ }^{4}$ !

Também quando se aborda o tema da consciência moral apresenta-se uma conceituação e um entendimento nesses rumos:

A consciência é percebida como instância da inteligência (Einsicht), de decisão e de controle ao mesmo tempo. Neste amplo sentido, representa a consciência (Bewusstheit) moral, realizando-se continuamente na liberdade de decisão. Inteligência e liberdade compenetram-se reciprocamente. A consciência é, então, aquela instância na qual com livre convicção alguém se decide por um princípio de ação, por um sistema vigente de valores, e coteja com esta opção fundamental, e assim as controla, todas as decisões seguintes, que são enquadradas nas diretrizes para a ação (p. 17) ${ }^{1}$.

A consciência moral não é uma potência nem um hábito, mas um ato do nosso intelecto prático: o juízo através do qual ele aplica a luz dos primeiros princípios morais a cada um dos nossos atos, julgando sobre sua bondade ou maldade moral (p. 16) ${ }^{1}$.

(...) parece-me que fica intensamente acentuada a irredutibilidade da consciência a fatores puramente ambientais e sociais: todos agem de uma determinada maneira, esta maneira é legitimada e fortalecida socialmente, mas o contestador sente que deve agir diversamente, a qualquer custo, experimentando dentro de si um chamamento e um estímulo (valores, princípios, normas éticas) que não pode deixar de atender. Não lhe importa se mais tarde terá de aguentar as consequências (p. 19-20) ${ }^{1}$

a genuína atuação da consciência moral se situa em posição equidistante entre a 'criação' e o simples 'reflexo'. A consciência moral é o lugar em que se manifestam os valores morais à pessoa humana e onde se faz a aplicação a suas situações concretas: 'É a consciência que, de modo admirável, dá a conhecer esta lei, cujo cumprimento consiste no amor a Deus e ao próximo' (GS 16). Por outro lado, a consciência moral não só esclarece a situação pessoal à luz do valor objetivo, mas obriga e compromete a própria pessoa a agir na direção manifestada: 'O homem tem lei escrita por Deus, em cuja obediência consiste a dignidade humana e pela qual será julgado pessoalmente' (GS 16). A consciência moral é, por conseguinte, a mediação subjetiva necessária da moralidade. Não gera a moralidade (o bom e o mau), já que não cria a realidade. Tampouco, porém, reduz-se sua atuação à mera repetição asséptica dos valores objetivos. Por causa da sua força obrigatória e manifestativa, exerce função mediadora entre a realidade (valor objetivo) e a situação pessoal (p. 82) .

Além disso, compreende-se a consciência moral a partir da tríplice direção: "na direção das realidades humanas; na direção da raiz última de todas as coisas; na direção das profundezas do próprio humano" ${ }^{6}$. Vale dizer, a consciência se dá numa experiência de abertura para o outro, para Deus e para si próprio.

\footnotetext{
b. "A confusão entre unidade e uniformidade faz com que qualquer iniciativa, movimento ou palavra discordante sofra suspeita e seja alvo do denuncismo típico de tempos obscuros. Uma coisa é dissentir 'em’ Igreja, sentindo-se Igreja e na Igreja. Outra é dissentir 'da' Igreja estando fora dela. Por que temer o dissenso em questōes morais não ensinadas de modo definitivo? Por que sempre tomar posição a favor da lei e da autoridade eclesial? Se a consciência é o sacrário secretíssimo onde ressoa a voz de Deus, ela está acima do magistério como expressão vinculante da autoridade eclesial. Ora, a 'consciência é o primeiro de todos os vigários de Cristo’! (Catecismo da Igreja Católica, 1778 (...)). A autoridade eclesial consiste em apoiar as consciências na busca da verdade, não impor-lha (cf. 2Cor 13,10). Sua intransigência escandaliza os pequeninos (1Cor 10, 23-33). A interpretação rigorista da novidade cristã afasta as pessoas de Deus (Santo Afonso de Ligório). O apego obsessivo às normas e princípios manifesta falta de confiança na capacidade humana de discernimento" (p. 349-50)3. O teólogo espanhol Azpitarte, em reflexão sobre conflitos e magistério da Igreja, afirma: "Quero dizer que a ética normativa, como conjunto de valores, não tem sido configurada de maneira definitiva e para sempre, mas está submetida também a um processo evolutivo. As mudanças culturais e científicas fazem com que nos aproximemos da realidade a partir de uma óptica diferente. Não no sentido de uma mudança constante, como se a moral fosse uma vareta nas mãos do vento que sopra, mas uma atitude de busca permanente para responder em cada situação, de forma mais humana e evangélica, aos problemas que se apresentam. A vida cansada que necessita distanciar-se dos objetos, para contemplá-los melhor, será um defeito orgânico, mas se converte em uma condição necessária para olhar com lucidez os acontecimentos da história. Esta evolução histórica tem que provocar necessariamente momentos de crise e vacilação, pois toda mudança rompe a estabilidade conseguida e supõe um desajuste entre o novo e a norma aceita anteriormente" (p. 365) ${ }^{4}$.
} 
Estudando os teólogos que tratam da consciência moral, percebe-se que o ser humano não pode ser alienado, fantoche, passivo, negligente, ingênuo, aprisionado por fatores externos ${ }^{c}$ etc., quando se trata da ação consciente e responsável em vista de uma decisão ética. Ademais, a vivência de uma vida pessoal, comunitária e social consciente ocorre baseada em um juizo interior sobre uma prática determinada, antes ou depois de que ela aconteça. Esse juízo ético valora a ação a partir da preocupação que aponta para uma prática de responsabilidade ou não, por exemplo, a defesa ou sustentabilidade da vida digna e justa.

Também quando se estuda o tema da consciência moral, à luz da neurociência, se levantam questóes como: antes de pensar numa ação humana com responsabilidade não se pode esquecer que ela pressupõe uma consciência, tendo o entendimento de que o que vivemos, sentimos, praticamos e somos emerge de um corpo e (também) de um cérebro, o que é um desafio a ser aprofundado; toda ação não pode ser compreendida ou valorada com relevância ética, jurídica e científica, prescindindo de um entendimento de como ela é determinada, condicionada pela singularidade cerebral, ou seja, a ação moral depende, entre outros fatores, do funcionamento dos circuitos neuronais (p. 161-2)

Em certos casos de disfunção cerebral, até a mais exercitada deliberação pode não ser capaz de sobrepujar forças não conscientes ou conscientes. Mal começamos a vislumbrar o perfil desses casos, mas sabemos, por exemplo, que pacientes com certos tipos de lesão pré-frontal podem ser incapazes de controlar a impulsividade. $\mathrm{O}$ modo como tais indivíduos controlam suas ações não é normal. Como devem ser julgados quando postos nas mãos da justiça? Como criminosos ou doentes neurológicos? Talvez as duas coisas, eu diria. Sua doença neurológica não deveria, de modo algum, desculpar suas ações, mesmo que pudessem explicar aspectos de um crime. Mas se eles têm uma doença neurológica, são de fato pacientes, e é nessa condição que a sociedade deve lidar com eles. (...) Outros pacientes, cuja lesão pré-frontal concentra-se no setor ventromedial, julgam dilemas morais hipotéticos de um modo muito prático e utilitário que tem pouca ou nenhuma aplicação para o lado mais humanitário do nosso espírito. Quando confrontados, por exemplo, com um suposto caso de tentativa de assassinato que fracassou apesar da intenção de matar, eles não julgam que a situação seja significativamente diferente de um homicídio involuntário, impremeditado. Podem, inclusive, achar a primeira dessas situaçôes mais permissível. O modo como tais indivíduos entendem as motivações, intenções e consequências é inconvencional, para dizer o mínimo, mesmo que em seu dia a dia eles provavelmente não sejam capazes de fazer mal a uma mosca. Ainda temos muito que aprender sobre como o cérebro humano processa os julgamentos de comportamentos e controla as açôes (p. 345-6, grifo nosso) $)^{\mathrm{d}, 9}$.

De que forma tratar temas como, por exemplo, o livre-arbítrio ou a liberdade para decidir se o ser humano é também determinação cerebral? Assim como também não se pode confundir os grupos neuronais, sincrônicos ou não, com a consciência - o que é consciente tem a ver com o organismo inteiro de um indivíduo, o qual tem um corpo, um cérebro, uma história e vive imerso num

c. Apesar de se reconhecer condicionamentos que todos sofrem pelo poder midiático e pelos fatores sociológicos, psicológicos e genéticos ${ }^{7}$.

d. "Em diversos estudos publicados ao longo das duas últimas décadas, o nosso grupo de investigação, bem como outros grupos, tem mostrado que quando indivíduos que eram inteiramente normais sofrem lesōes em regiōes cerebrais necessárias para que ocorram certas emoções e sentimentos, perdem a capacidade de governar o seu comportamento na sociedade em que vivem. A capacidade de decisão, especialmente em situações de grande incerteza, está fortemente comprometida. Exemplo de decisōes tomadas em clima de incerteza incluem investimentos financeiros ou relaçōes humanas de amizade. Nesses doentes, rompem-se os contratos sociais. Frequentemente os casamentos dissolvem-se, as relações entre pais e filhos deterioram-se, e perdem-se também os empregos.

Uma vez estabelecidas as lesões cerebrais, esses doentes deixam de ser capazes de manter o seu status quo e perdem a sua independência financeira. É raro que se tornem violentos, e em suas rupturas do contrato social eles tendem a não desrespeitar as leis propriamente ditas, embora desrespeitem por certo as convençôes sociais. No entanto, o governo geral da sua vida é profundamente afetado. É fácil ver que, sem ajuda de outros, o bem-estar e até a sobrevida desses doentes não seriam de todo possíveis.

O doente típico com esse tipo de problema tinha sido, antes do começo da doença, um indivíduo socialmente exemplar. Trabalhador, bem-sucedido, capaz de atividades altamente competentes e de obter a larga recompensa financeira que acompanha tais qualidades. Alguns dos doentes que estudamos tinham até atividade notável em matéria de vida social e eram vistos por outros como pilares da comunidade. Um vez que as lesōes pré-frontais têm lugar, contudo, tais personalidades modificam-se de forma notável. (...)

Uma das áreas de maior dificuldade para esses doentes diz respeito às relaçôes sociais. Não é fácil para eles decidir em quem devem ter confiança ou de quem devem desconfiar. Falta-lhes o sentido daquilo que é socialmente permissivel, por vezes de forma altamente embaraçosa. Não observam certas convenções sociais e podem também não observar certas regras da ética" (p. 150-1, grifo nosso) ${ }^{10}$. 
contexto determinado; enfim, "a consciência não está na cabeça” (p. 246-50) ${ }^{11}$.

$\mathrm{Na}$ busca de superar uma visão de consciência moral alicerçada em pressupostos antropológicos idealistas, em uma racionalidade ético-teológica abstrata e cartesiana ${ }^{\mathrm{e}}$ pouco pertinente e irresponsável, abstrata e universal, e por uma praticidade defasada e irrelevante, procurar-se-á refletir os seguintes aspectos: o que a neurociência apresenta a respeito do que é a consciência; como falar de uma liberdade para agir com consciência ética e que consequências se podem tirar para a visão ou concepção de consciência moral mais profunda e responsável para a atualidadef; em que ilumina a neurociência quando, a respeito de uma decisão da consciência moral, se pressupõe discernimento, livre decisão, juízo de valor, deliberação e liberdade; que consequências surgem para a consciência moral cristá.

\section{O QUE ENTENDER POR CONSCIÊNCIA E $O$ ELO COM A CONSCIÊNCIA MORAL}

Quando estudamos a respeito da "consciência moral" nos defrontamos com a temática da consciênciag ${ }^{\mathrm{g}}$, entendendo por consciência "uma cum-scientia (ver com; conhecer com), uma sabedoria que vai crescendo na exata medida em que o eu se abre àquilo que aparentemente lhe é externo, mas que penetra mais ou menos profundamente no próprio ser" (p. 155) permeia um agir ético tem a ver também com a dinâmica cerebral:

O fato de agir de acordo com um dado princípio ético requerer a participação de circuitos modestos no cerne do cérebro não empobrece esse princípio ético. O edifício da ética não desaba, a moralidade não está ameaçada e, num indivíduo normal, a vontade continua a ser vontade. $\mathrm{O}$ que pode mudar é a nossa perspectiva acerca da maneira como a biologia tem con- tribuído para a origem de certos princípios éticos que emergem num determinado contexto social, quando muitos indivíduos com uma propensão biológica semelhante interagem em determinadas circunstâncias (p. 14) $)^{12}$.

Ao entrar pela porta da neurociência, depara-se com a definição de que

consciência é um estado mental no qual existe o conhecimento da própria existência e da existência do mundo circundante. Consciência é um estado mental - se não há mente, não há consciência; consciência é um estado mental específico, enriquecido por uma sensação do organismo específico no qual a mente atua; e o estado mental inclui o conhecimento que situa essa existência: o conhecimento de que existem objetos e eventos ao redor. Consciência é um estado mental ao qual foi adicionado o processo do self (p. 197) .

E mais: a consciência

é o termo abrangente para designar os fenômenos mentais que permitem o estranho processo que faz de você o observador ou o conhecedor das coisas observadas, o proprietário dos pensamentos formados de sua perspectiva, o agente em potencial. A consciência não é externa a este processo, é uma parte de seu processo mental. Perspectiva individual, propriedade individual do pensamento e condição de agente individual são riquezas cruciais com que a consciência central contribui para o processo mental que ocorre agora em seu organismo. A essência da consciência central é o próprio pensamento em que você - o próprio sentimento de si - é um indivíduo sendo envolvido no processo de tomar conhecimento de sua própria existência e da existência de outros (p. 169) ${ }^{13}$.

Experiência que é vivida desde a perspectiva exclusiva e privada de um ser humano, por pertencer a um organismo particular.

e. "É esse o erro de Descartes: a separação abissal entre o corpo e a mente, entre a substância corporal, infinitamente divisível, com volume, com dimensões e com um funcionamento mecânico, de um lado, e a substância mental, indivisível, sem volume, sem dimensôes e intangível, de outro; a sugestão de que o raciocínio, o juízo moral e o sofrimento adveniente da dor física ou agitação emocional poderiam existir independentemente do corpo. Especificamente: a separação das operações mais refinadas da mente, para um lado, e da estrutura e funcionamento do organismo biológico, para o outro" (p. 280) 12. $^{2}$.

f. Importante ter ciente que a consciência moral requer a consciência, apesar de "ir muito além dela” e, ao mesmo tempo, pertencer à esfera do agir responsável.

g. "Consciência não é consciência moral. Não é o mesmo que amor, honra e misericórdia, generosidade e altruísmo, poesia e ciência, matemática e invenção técnica. A propósito, torpeza moral, angústia existencial e falta de criatividade também não são exemplos de estados de consciência ruins. A consciência da maioria dos criminosos não está comprometida. Sua consciência moral pode estar" (p. 390) ${ }^{13}$. Desde já é fundamental ter claro que consciência e consciência moral são distinguíveis. Consciência tem a ver com o conhecimento de um objeto ou de uma ação atribuída ao self, ao passo que consciência moral concerne ao bem e ao mal que o sujeito pode discernir em ações ou objetos. 
Também há que esclarecerem duas realidades importantes quando se estudam os comportamentos éticos a partir da neurobiologia. Primeiro, não dá para entender um comportamento ético desenraizado do mundo das emoções e sentimentos. Inclusive, se afirma que

as emoções e os sentimentos terão sido um alicerce necessário para os comportamentos éticos muito antes de os seres humanos terem iniciado a construção deliberada de normas inteligentes de conduta social. As emoçóes e os sentimentos teriam começado a fazer parte dos organismos complexos em etapas evolucionárias anteriores, que dizem respeito a espécies não humanas, e teriam sido um fator importante no estabelecimento de estratégias cognitivas de cooperação (p. 172) ${ }^{10}$.

Segundo, ao tratar dos mecanismos biológicos que alicerçam os comportamentos éticos, há que dizer que esses mecanismos não são a causa de um comportamento ético:

O fato de que contribuem para o comportamento não significa que sejam, necessariamente, determinantes desse comportamento. Creio, evidentemente, que os comportamentos éticos dependem da atividade de certos sistemas cerebrais. Mas esses sistemas não são centros. Não dispomos de um centro ou centros de moral. Nem mesmo a região ventromedial do córtex pré-frontal, cuja importância para os comportamentos éticos é óbvia, deve ser considerada um centro. Além disso, os sistemas que apoiam os comportamentos éticos não começaram a sua existência neural com uma dedicação exclusiva à ética. No fundo, são sistemas dedicados à regulação biológica, à memória, à decisão e à criatividade. Os comportamentos éticos são, eles mesmos, o resultado de certas sinergias entre essas atividades (p. 177) ${ }^{10}$.

Tratar do tema da consciência nos lança ao trabalho de distinguir os tipos de consciência. Em neurociência, se fala da consciência central e da consciência ampliada:

Dei nomes a esses dois tipos de consciência. A de abrangência mínima chamei de consciência central, o sentimento do aqui-agora, desembaraçado de muito passado e futuro. Ela gira em torno de um self central e nos dá a pessoalidade, mas não necessariamente uma identidade. A de grande abrangência chamei de consciência ampliada ou autobiográfica, pois ela se manifesta mais acentuadamente quando uma parte substancial da nossa vida está acontecendo, e tanto o passado vivenciado como o futuro esperado dominam a ação. Ela nos dá a pessoalidade e uma identidade. É presidida pelo self autobiográfico (p. 211)9.

Não há dúvida de que o suporte básico da consciência passa pela "consciência central", mas seu ápice ou sua glória tem a ver com a "consciência ampliada". Por isso se afirma que quando se pensa

na grandiosidade da consciência, o que temos em mente é a consciência ampliada. Quando cometemos o deslize de dizer que a consciência é uma qualidade distintivamente humana, estamos pensando na consciência ampliada em seus níveis mais elevados, não na consciência central, e por isso nossa arrogância é perdoável: a consciência ampliada é de fato uma função prodigiosa e, em seu ápice, ela é exclusivamente humana.

A consciência ampliada vai além do aqui e agora da consciência central, em direção tanto ao passado como ao futuro. O aqui e agora ainda é importante, mas flanqueado pelo passado, voltando no tempo tanto quanto possa ser necessário para iluminar eficazmente o agora; de modo igualmente importante, ela é flanqueada pelo futuro antevisto. Em seu auge, o campo de ação da consciência ampliada pode abranger todo o período de vida do indivíduo, do berço aos dias futuros, e ainda situar paralelamente o mundo. Em um dia qualquer, se você lhe der asas, a consciência ampliada pode fazer de você um personagem de romance épico e, se você a usar bem, ela pode lhe abrir as portas da criação.

A consciência ampliada é tudo o que a consciência central é, só que maior e melhor, e só faz crescer com a evolução e com as experiências q ue cada indivíduo tem ao longo da vida. Se a consciência central permite que você saiba, por um momento fugaz, que é você quem está vendo um pássaro voando ou quem está sentindo uma dor, a consciência ampliada situa essas mesmas experiências em um contexto mais amplo e em um intervalo de tempo mais longo. A consciência 
ampliada ainda gira em torno do mesmo 'você' central, mas esse 'você' agora está conectado ao passado vivido e ao futuro antevisto, partes de seu registro autobiográfico. Em vez de apenas ter acesso ao fato de que está sentindo dor, você também pode fazer um levantamento dos fatos relacionados ao local da dor (o cotovelo), ao que a causou (tênis), quando a sentiu pela última vez (faz três anos - ou serão quatro?), quem também sentiu uma dor assim recentemente (sua tia Maria), o médico que ela procurou (o dr. Silva - ou terá sido o dr. Castro?), o fato de que você não poderá jogar com o João amanhã. $\mathrm{O}$ espectro de conhecimento que a consciência ampliada permite que você acesse agora abrange um vasto panorama (p. 251-2 $)^{13}$.

$\mathrm{Na}$ consciência ampliada, ocorre uma organização em que as memórias autobiográficas são objetos, e o cérebro permite que elas se relacionem com o organismo, gerando um "pulso de consciência central", um sentido do self no ato de conhecer. Em outras palavras, através da consciência ampliada o ser humano adquire a capacidade de aprender e guardar registros de uma infinidade de experiências; e, ao mesmo tempo, o poder de reativar os registros de maneira que possam gerar "um sentido no self no ato de conhecer".

Agora se pode levantar a questão: onde fica a consciência moral nisso tudo? Em cima de que encadeamento se pode pensar nela? A neurociência afirma que a consciência ampliada favorece aos organismos humanos chegarem ao ápice de suas capacidades mentais. Dentre essas capacidades, destacam-se: capacidade de viver a solidariedade com o outro, saber valorizar e defender a vida, sintonizar com os interesses da coletividade, viver uma indignação diante da injustiça social, ter senso do que é a verdade e o bem ou o que é a mentira e o mal. Nesse conjunto de capacidades implementadas pela consciência ampliada, cabe destacar a capacidade de elevar-se acima dos ditames da vantagem e da desvantagem impostos pelas necessidades de sobrevivência e, segunda, a percepção crítica de discordâncias, que leva à busca da verdade e ao desejo de criar normas e ideais para o comportamento e para a análise dos fatos. Essas duas capacidades não são apenas minhas melhores candidatas ao ápice da distinção humana, mas são também as que possibilitam a função verdadeiramente humana, captada com tanta perfeição pela singular expressão consciência moral (p. 294-5) ${ }^{13}$.

Constata-se que a consciência é necessária, importante, mas não suficiente para alcançar o ápice. Daí poder apresentar o encadeamento de precedências que revela como se chega à consciência moral, ou melhor, o lugar fundamental dela. A dinâmica do encadeamento se dá no seguinte processo:

a sinalização neural inconsciente de um organismo individual gera o proto-self que possibilita o self central e a consciência central, que por sua vez possibilitam o self autobiográfico, o qual possibilita a consciência ampliada. No final dessa cadeia, a consciência ampliada possibilita a consciência moral (p. 295) ${ }^{\mathrm{h}, 13}$.

\section{A DINÂMICA COMPLEXA E RESPONSÁVEL PELO SURGIMENTO DA CONSCIÊNCIA "VIVIDA"I}

Partindo da constatação de que não se pode entender a consciência, menos ainda a consciência moral, apenas como resultado de processos neuronais - apesar de ser na atualidade imprescindível conhecer como funciona a dinâmica cerebral, urge aprofundar a dinâmica responsável pela experiência de uma vida de e com consciência, o que implicará uma compreensão mais profunda do que é viver a partir da consciência moral. A consciência não pode surgir e nem pode ser compreendida somente pela esfera cerebral - a realidade neuronal não tem

h. O autor, a respeito da "consciência central”, faz o seguinte comentário: "A consciência central não ocupa uma posição especialmente elevada na ordem das operações que permitem que os seres humanos sejam o que são. Ela faz parte do alicerce de um edifício complexo, não do ápice da torre. A consciência central situa-se acima, mas não muito distante, de outras capacidades fundamentais, como ação, emoção e representação sensorial, capacidades que compartilhamos com várias espécies não humanas” (p. 392) ${ }^{13}$.

i. A reflexāo que segue nesse item é sumamente devedora da reflexão de Francisco Varela ${ }^{11}$. Também é importante a observação de António Damásio: "Quando pensadores tão diversos quanto Daniel Dennett, Humberto Maturama e Francisco Varela falam em consciência, geralmente estão falando de consciência como um fenômeno pós-linguístico. Eles estão falando, a meu ver, dos níveis superiores da consciência ampliada conforme ela ocorre agora, nesta etapa da evolução biológica. Não faço objeções às suas teorias, mas quero deixar claro que na minha concepção a consciência ampliada se assenta sobre o alicerce da consciência central que nós e outras espécies possuímos há muito tempo e que continuamos a possuir" (p. 242) ${ }^{13}$. 
consciência e não é consciência! Lógico, ela é realidade fundamental no surgimento da consciência. A consciência não é apenas o funcionamento de um conjunto de neurônios.

Então, o que entender por consciência? Tratar da consciência é considerar o organismo inteiro, o qual tem um cérebro, um corpo e que está inserido numa história e num mundo. Nesse aspecto, compreender a consciência é entendê-la inserida num "viver encarnado" do organismo como um todo, e não de suas partes. Ou seja, afirmar que a consciência emerge no viver encarnado implica dizer que no organismo ocorrem relaçôes estreitas de "acoplamento", de conexão, tanto no nível interno entre suas partes, como do organismo com o mundo, e que é por essas relações de "acoplamento", conexões e interações que surge a possibilidade da consciência.

Essas relações de "acoplamento", conexão pelo organismo ocorrem ao menos de três modos, os quais são essenciais para o surgimento de um organismo consciente (p. 246-7) ${ }^{11}$ :

Um primeiro modo parte da compreensão de que o cérebro não é uma realidade isolada, ao contrário, está em íntima relação com todo o corpo. Não só o levamos dentro do corpo, senão que o cérebro estabelece relações específicas de regulação com todos os órgãos, regulação da temperatura, do oxigênio no sangue, do pulsar do coração, do funcionamento do intestino, do suor da pele, do sistema de imunidade etc., e o corpo por sua vez interfere no funcionamento do cérebro. Ocorre uma correspondência muito grande nesse círculo entre cérebro e corpo. Enfim, o cérebro se apresenta imerso em uma unidade corporal que é o organismo.

Segundo, o organismo tampouco está isolado. Ele está imerso em um mundo. Estabelece com o mundo "relaçôes sensorimotoras", vale dizer, continuamente está ativo, se move, percebe, relaciona com as coisas, comunica, escuta, sente o mundo e atua sobre ele, sempre a partir do círculo de ação organismo-mundo fundamental. Existe uma atividade continua de estar e mover-se no mundo, de adaptar-se a uma situação que está permanentemente mudando.
Terceiro, os seres humanos não vivem no mundo apenas manejando objetos. $\mathrm{Na}$ verdade vivemos imersos em mundo muito particular de relaçôes com outros seres humanos. Vive-se em uma rede intersubjetiva (entre sujeitos) de ações e linguagem que condicionam o que vemos, como vemos, o que reconhecemos como válido e, em última instância, o que nos faz sentido como seres humanos. Esse "novo círculo intersubjetivo" está na base do que entendemos por consciência, e de nossa constituição como seres conscientes.

Esses três aspectos apresentados, a vida social ou de relaçôes humanas, a vida de ações no mundo e a vida da regulação orgânica interna são as grandes instâncias que constantemente estão unidas. Não resta dúvida de que as sincronias neuronais são necessárias para que ocorra a dinâmica dessas instâncias, mas é parte do processo do ser consciente. Vejamos a conclusão de que "a consciência não está na cabeça”, segundo o neurobiólogo Varela:

A posição que eu defendo é que a sincronia cerebral e sua operação dinâmica é uma condição de possibilidade para o aparecimento da consciência, mas não é condição suficiente. Falar de uma condição de possibilidade quer dizer que si não temos a capacidade de por em harmonia as diferentes facetas de nossa atividade cognitiva, seja corporal, de ação ou de relação social, obviamente não podemos ser conscientes no mundo, mas o fato de que temos essa capacidade, através das sincronias neuronais, não basta por si só para que a consciência emerja. Uma maneira de ilustrar isto é através de um exemplo muito simples: quando escutamos o rádio, seus circuitos são a condição de possibilidade de que eu escute, são imprescindíveis, mas o que o que se ouve no rádio não está nos circuitos, como tampouco está no rádio o sentido das palavras.

As sincronias cerebrais são essenciais, é uma condição de possibilidade sine qua non, já que quando ocorre problemas nas sincronias neuronais ou em sua operação dinâmica, a consciência funciona mal ou não funciona, como ocorre segundo vimos no caso da anestesia geral. Só a partir da condição de que se tem cumprido a condição de possibilidade 
que se permite poder estabelecer os ciclos de acoplamento do cérebro com o corpo, do organismo com o mundo e do organismo com suas partes, é que pode emergir a consciência. É justamente nos ciclos de acoplamento donde emerge e no dentro da cabeça, a consciência está na interfase, não está nem dentro nem fora, está no encontro, na união do organismo, que tem um cérebro imerso em seu corpo, com o mundo físico. Isto é, com certeza, um exemplo notável do que se conhece como 'fenômenos emergentes' na teoria de sistemas dinâmicos: temos uma série de elementos locais (neurônios, cérebro, corpo, mundo físico) que quando se acoplam, quando entram em relação, dão origem a um fenômeno que não é a mera soma das partes, senão uma globalidade em si, distinta e unitária, e que modifica o funcionar dos elementos sem ser redutível a eles. Por mais que busquemos este fenômeno global, não o podemos encontrar em nenhuma das partes em particular, já que, justamente, emerge na interação de todas elas (p. 249-50) ${ }^{11}$.

Pensar que para compreender como emerge e funciona a consciência basta detectá-la na cabeça leva a uma "falsidade absoluta" ou a uma ilusão, porque, assim, acaba negando que a consciência se dá dentro de uma complexidadej. Seria puro reducionismo e/ou uma visão pouco científica e responsável; vale afirmar, a posição apresentada vai contra a de tese de F. Crick, a qual afirma que conhecendo os "correlatos neuronais" se consegue explicar o fenômeno da consciência ${ }^{14}$.

Enfim, para poder avançar num estudo sério e completo a respeito da consciência, é imprescindível levar a sério a interação com o sujeito. $\mathrm{E}$, ainda, devolver, ao laboratório, o lugar de honra que deve ter a experiência vivida. Há que considerar o que o sujeito vive, o que ele experimenta e pode expressar e relatar como observado por si mesmo. Tradicionalmente, não se confia nesses dados, como se fossem dados subjetivos, e subjetivo tem sempre a característica de arbitrário. Isso é um tabu absurdo, porque a experiência vivida, o subjetivo, é parte da natureza, e por isso pode ser expressada, estudada e validada. Essa aproximação é o que se conhece como o estudo fenomenológico da consciência e quais são as descrições que posso fazer sobre a estrutura da minha experiência. A ideia primeira é levar a sério e de maneira rigorosa os dados em primeira pessoa, o que eu vejo, ou, no caso do sujeito, o que ele experimenta em sua vivência e nos comunica por meio de um relato detalhado.

Com base nisso, surge a proposta concreta: só por meio do estudo neuro-fenomenológico (mediante o registro da atividade cerebral e o relato detalhado da experiência vivida em uma mesma experiência) pode-se construir a ponte e começar a compreender realmente como emerge a consciência (p. 250-1) $)^{11}$.

Também tem se estudado a consciência a partir da "teoria holoinformacional"15. Segundo essa teoria, não se pode entender a consciência a não ser partindo do

j. O estudo sobre a consciência pode ser encontrado em várias escolas ou correntes de pensamento, depende do método que se utiliza - "A primeira corrente de pensamento é a mais tradicional. Conta entre seus membros a neurocientista Patrícia Churchland e o biólogo molecular Francis Crick... Essa escola foi chamada de 'neurorreducionistả por Francisco Varela, pois reduz a consciência aos mecanismos nervosos. Assim, a consciência é 'desexplicada', como diz Churchland, da mesma maneira que, na física, o calor foi 'deseplicado' quando foi identificado à pura e simples energia das moléculas em movimento. Nas palavras de Francis Crick: 'Vocể, suas alegrias e tristezas, suas memórias e ambiçôes, sua noção de identidade pessoal e livre-arbítrio, não passam, na verdade, da resultante comportamental de um grande conjunto de células nervosas e das moléculas a elas associadas. Como Alice de Lewis Carroll teria dito: 'Você' não passa de um saco de neurônios'.

Crick explica detalhadamente como a consciência se reduz à ativação dos neurônios, mas também afirma que a experiência consciente é uma propriedade emergente do cérebro como um todo. Contudo, não chega a tratar da dinâmica não-linear desse processo de surgimento espontâneo de uma nova propriedade, e não consegue, desse modo, roer o 'osso duro' da ciência da consciência. (...) A segunda corrente de estudo da consciência, chamada de 'funcionalismo', é a mais popular dentre os filósofos e estudiosos da cognição de hoje em dia. Seus defensores afirmam que os estados mentais são definidos pela sua 'organizaçẫo funcional', ou seja, por padrōes de relaçōes causais no sistema nervoso. Os funcionalistas não são reducionistas cartesianos, pois prestam cuidadosa atenção aos padrões nervosos não-lineares. Negam, porém, que a experiência consciente seja um fenômeno emergente e irredutível. Pode até parecer que não se reduz a nenhum outro fenômeno; mas, na opinião deles, o estado de consciência se define completamente pela organizaçăo funcional, e, portanto, pode ser compreendido no mesmo momento em que essa organizaçăo é identificada... (...) Bem menos conhecida é a escola filosófica dos chamados 'misterianos'. Afirmam eles que a consciência é um mistério profundo, o qual a inteligência humana, em virtude de suas limitaçôes intrínsecas é uma dualidade irredutível - que, na prática, não é outra senão a clássica dualidade cartesiana entre mente e a matéria. Se a introspecção não pode nos dizer nada acerca do cérebro enquanto objeto físico, também o estudo da estrutura cerebral não pode nos abrir nenhum acesso à experiência consciente. Como se negam a conceber a consciência como um processo e não compreendem a natureza dos fenômenos emergentes, os misterianos são incapazes de transpor o abismo cartesiano e chegam à conclusão de que a natureza da consciência será para sempre um mistério. Por fim, há uma corrente de estudos da consciência que, embora pequena, vem crescendo bastante, e que faz uso tanto da teoria da complexidade quanto dos relatos em primeira pessoa. Francisco Varela, um dos fundadores dessa escola de pensamento, deu-lhe o nome de 'neurofenomenologiả. (...) A neurofenomenologia, pois, é um método de estudo da consciência que combina em si o exame disciplinado das experiências subjetivas com a análise dos padrōes e processos neurais correspondentes. A partir dessa abordagem dual, os neurofenomenologistas exploram diversos domínios de experiência subjetiva e procuram compreender de que maneira eles surgem espontaneamente a partir de atividades neurais complexas" (p. 58-60) ${ }^{14}$. 
"holomovimento"k, que proporciona uma auto-organização de vários níveis (matéria, vida, natureza, etc.) que concorrem para a estruturação da consciência. Ou seja, "como a consciência sempre esteve presente nos diversos níveis de organização da natureza, matéria, vida e consciência não podem ser consideradas entidades separadas - os vários níveis -, capazes de serem analisadas em um arcabouço conceitual cartesiano fragmentador. Com efeito, devem ser consideradas como uma unidade indivisivel, com todos os seus processos quântico-informacionais interagindo por meio de relaçôes não-locais (holísticas), internas e simultaneamente por meio de relações externas locais (mecanicísticas), gerando capacidades de transformação, aprendizagem e evolução. Essa visão de um continuum holoinformacional, de uma ordem geradora fundamental, com um fluxo quântico-informacional criador, permeando todo o cosmos, permite compreender a natureza básica do universo como uma totalidade inteligente auto-organizadora indivisivel, ou seja, uma consciência, uma forma de consciência universal se desdobrando de modo 'holográfico' em uma infinita holoarquia.

As flutuações quântico-informacionais geradas a partir desta consciência universal através do holomovimento se auto-organizam nos níveis informacionais básicos do universo: o código nuclear (cosmofera), o código genético (biosfera) e o código neural (noosfera). Estes códigos holoinformacionais, ou seja, esta ordem que é transmitida de um modo significativo e inteligente através de todos os níveis de complexidade do universo, são a auto-organização neguentrópica da informação. Nesta visão holoinformacional da consciência, $o$ fluxo quântico-informacional não-local, em um contínuo holomovimento de expansão e recolhimento, entre o cérebro e a ordem superimplícita do universo, é a consciência universal, se auto-organizando em mente humana (p. 258-9) ${ }^{15}$.

Enfim, o ser humano é consciência dentro desse grande, recriador, autorreferente, auto-organizador, complexo holomovimento. A consciência humana pode ser considerada um subsistema de um holograma universal, acessando e interpretando este universo holográfico. Somos sistemas interativos ressonantes e harmônicos, com esta totalidade auto-organizadora indivisível. Somos este campo holoinformacional da consciência, e não observadores externos a ela. A perspectiva de observadores externos nos fez perder o sentido e o sentimento da unidade ou identidade suprema, gerando as imensas dificuldades que temos para compreender que somos um com o todo, e não uma parte dela. 'Nós não viemos a este mundo: viemos dele, como as folhas de uma árvore. Tal como o oceano produz ondas, o universo produz pessoas. Cada indivíduo é uma expressão de todo o reino da natureza, uma ação singular do universo total. Raramente este fato é, se é que alguma vez chega a ser, sentido pela maioria dos indivíduos' (Alan Watts) (p. 263) $)^{15}$.

Essa visão holística, auto-organizadora e holoinformacional nos leva a superar uma visão paradigmática cartesiano-newtoniano reducionista, mecanicista e fragmentária, o que tem possibilitado uma compreensão míope, desumana e irresponsável diante da experiência humana.

\section{O AGIR MORAL E A DETERMINAC̣̃̃o CEREBRAL}

A natureza humana é constituída de algumas qualidades biológicas, anatômicas e apresenta certas manifestaçôes comportamentais inevitáveis em muitas situações. Algumas propriedades fixas da mente humana são inatas, o que favorece ao ser humano ter habilidades e destrezas que não são encontradas em outros seres vivos, contribuindo para a vivência de determinada condição humana, tudo resultado de um processo evolutivo inegável!

O problema que se coloca é: o ser humano traz consigo um sentido moral inato? Se isso é confirmado, pode-se reconhecê-lo e aceitá-lo sem condiçôes? Ou seja, se uma pessoa não mata o semelhante é porque matar não é uma coisa boa, e não porque Deus não permite ou porque vai contra as regras morais, ou porque as leis da sociedade vão puni-la. Daí o desafio que se apresenta:

k. A teoria do holomovimento foi desenvolvida pelo físico David Bohm. Ele "demonstra matematicamente a existência de uma ordem oculta, implícita, no universo, que seria a realidade primária. Matéria, vida e consciência (a ordem explícita) se originariam deste solo comum (a ordem implícita), por meio de um contínuo movimento de desdobramento (extrojeção) e recolhimento (introjeção) do cosmos, denominado holomovimento" (p. 254) ${ }^{15}$. 
compreender que a maioria dos sistemas morais e as crenças atuais provêm de teorias baseadas, quiçá, na lógica do que postularam sobre a natureza da realidade as melhores mentes de nossa espécie ao longo do tempo, como reação diante dos acontecimentos da vida. Para os que compreendem e creem em tal possibilidade, a tarefa do seres humanos modernos consiste em discernir si nossa natureza e nossa cultura, sumamente evoluídas, desfrutam de uma ética universal subjacente, uma resposta moral ante os desafios da vida, que tem sido um traço de nossa espécie desde o começo (p. 168-9) ${ }^{16}$.

Tudo aponta para o entendimento de que nossa espécie possui um sentido moral inerente, uma capacidade para emitir juízo de valor sobre o que é o bem e o que é o mal. E ainda: parecem existir uns instintos morais de alcance universal, os quais, por serem comuns, não se formulam em regras - por exemplo, que não se deve praticar o incesto e dizer mentiras, não abandonar as crianças e ser fiel à família ${ }^{17}$.

Nesse sentido, alguns cientistas ${ }^{16,17}$ apontam para a tese de que a moral não pode ser compreendida como uma mera construção social ou de que se age apenas por meros fatores externos. Antes de cumprir ou viver um compromisso há que existir uma disposição interna, como exemplo, a boa vontade, a disposição. Por isso, uma ação pode ser boa ou má, ajudar ou não a vida, dependendo de como assumimos as tarefas com mais ou menos vontade, com mais ou menos sentimentos e emoção. A razão humana é codeterminada também pela disposição positiva ou negativa provinda do mundo dos sentimentos e das emoções. Sendo assim, é

surpreendente e inédito que a ausência de emoções não seja menos incapacitadora nem menos suscetível de comprometer a racionalidade que nos torna distintamente humanos e nos permite decidir em conformidade com um sentido de futuro pessoal, convenção social e princípio moral. Tampouco se pretende afirmar que, quando têm uma ação positiva, as emoções tomam as decisões por nós ou que não somos seres racionais. Limito-me a sugerir que certos aspectos do processo da emoção e do sentimento são indispensáveis para a racionalidade. No que têm de melhor, os sentimentos encaminham-nos na direção correta, levam-nos para o lugar apropriado do espaço de tomada de decisão onde podemos tirar partido dos instrumentos da lógica. Somos confrontados com a incerteza quando temos de fazer um juízo moral, decidir o rumo de uma relação pessoal, escolher meios que impeçam a nossa pobreza na velhice ou planejar a vida que se nos apresenta pela frente. As emoçôes e os sentimentos, juntamente com a oculta maquinaria fisiológica que lhes está subjacente, auxiliam-nos na assustadora tarefa de fazer previsōes relativamente a um futuro incerto e planejar as nossas ações de acordo com essas previsões (p. 12-3) ${ }^{12}$.

O ser humano quando atua numa determinada situação de acordo ou não com um critério moral é porque (também) o aspecto emocional do seu cérebro foi ativado ao pensar na questão moral. Isso é uma "novidade surpreendente", pelo fato de que o cérebro pode encaminhar ou favorecer uma decisão automática independente de uma resposta moral alicerçada na pura razão humana.

Desde uma perspectiva evolutiva, a teoria é que as estruturas neuronais que associam os instintos com a emoção se selecionaram ao longo do tempo porque era benefício ajudar o ser humano de modo imediato. $\mathrm{O}$ instinto visceral, ou moral, é o resultado de processos selecionados ao longo do processo evolutivo. Temos processos cognitivos que nos permitem tomar decisões morais rápidas que aumentarão nossa probabilidade de sobrevivência. Se estamos programados para salvar um indivíduo que temos em frente, todos sobreviveremos melhor. No caso do uso do dinheiro, o altruísmo à distância não é tão necessário; o que os olhos não veem, o coração não sente. Não uma necessidade extrema (p. $172)^{1,16}$.

1. Com liberdade utilizamos as reflexōes do autor. O neurocientista Gazzaniga afirma que: "La investigación sobre la cognición moral aborda tres temas principales: las emociones Morales, la teoria de la mente y el razonamiento moral abstracto. Las emociones Morales - las que motivan la conducta - son, sobre todo, producto del tallo cerebral y del eje límbico, que regulan instintos básicos tales como el sexo, el alimento, la sed, etc. 'Teoria de la mente' es el término que usamos para describir nuestra capacidad de evaluar lo que están pensando los demás con el fin de actuar ante ellos de manera adecuada; se trata de un razonamiento moral esencial, porque orienta nuestra conducta social. Se cree que las 'neuronas espejo'... - el córtex frontal orbital, las estructuras intermédias de la amígdalas y el surco temporal superior - son las responsables de los procesos de la teoria de la mente. Por último, la imagen cerebral nos muestra que el razonamiento moral abstracto utiliza muchos sistemas del cerebro" (p. 172) ${ }^{16}$. 
Essa realidade coloca a questão central de se as verdades morais são realmente universais ou são meras opiniōes, instintos viscerais individuais. Tudo parece indicar que, pelo menos em algumas situações, o cérebro parece responder aos dilemas morais subjacentes. Parece haver mecanismos subconscientes comuns que ativa a vida do ser humano diante de alguns desafios morais.

Concluindo, é possível dizer que, em alguns casos em que devemos tomar uma decisão moral, a decisão pode ser fruto de juízos intuitivos; vale dizer, reagimos automaticamente - uma resposta que nasce do cérebro. Importante é perceber que muitas atitudes que temos nascem instintivamente na luta pela sobrevivência ou pelo fato de guardarmos dentro de nós um "espírito" humanitário - muitas vezes independente de normas morais ou leis instituídas pela sociedade. Contudo, não esqueçamos que o cérebro é uma realidade em contínua interação com toda a realidade que nos circunda ou da qual fazemos parte. Por isso, toda ação moral, por mais que seja decidida mediante uma função cerebral, ela se dá dentro de uma liberdade e de uma responsabilidade, e de uma interação da parte com o todo, vale dizer, dentro da dinâmica do holomovimento. Por isso, as decisōes diante da vida, antes de serem somente por princípios, acontecem por uma dinâmica existencial, societária e cósmica. Sendo assim, a experiência do ser consciente requer mais do que um cérebro, e, sobretudo de um cérebro isolado. $\mathrm{O}$ cérebro, a todo momento, é um processo reorganizacional de acordo com a totalidade do existente.

\section{AS CONSEQUÊNCIAS PARA A CONSCIÊNCIA MORAL}

Se partirmos do entendimento de que a natureza e a função da consciência, numa perspectiva fenomenológica, têm a ver com o juizo de avaliação, do qual redunda sentimento de aprovação ou reprovação; que sua natureza se dá na esfera cognoscitiva: em que o ser humano é sujeito do seu próprio ato ou de sua atitude e, portanto, um conhecimento reflexo ocorre (p. 469) ${ }^{18}$, pode-se concluir que a consciência moral é resultado de uma reflexão $\mathrm{em}$ cima do ou reflexão a partir do próprio agir ${ }^{\mathrm{m}}$.

Essa realidade aponta, necessariamente, para a relevância de uma compreensão de que nossa consciência moral é determinada pela realidade cerebral. Não esquecendo que ela também é determinada por normas morais e/ou princípios adquiridos no contexto sociocultural, além da interação com tudo que determina a vida humana. $\mathrm{O}$ mais importante, no entanto, é constatar que o ser humano se apresenta como sujeito de significação e valores pelos quais se vai fazendo presença na história e interpretando o mundo existente.

Aqui cabe destacar o "caráter projetivo da consciência". O sujeito se percebe como fonte de verdade, de bem, de valor. Os valores objetivos assumem sentido e significado na medida em que são percebidos, captados pelo sujeito. O sujeito vê que seu respeito pela objetividade é, em última análise, um respeito a si mesmo, a sua consciência. Portanto, a verdade se apresenta fundamentalmente como exigência do sujeito e não do objeto, ainda que esse tenha seu caráter compacto de existência.

Os fatos, a realidade se fazem verdade, isto é, são conhecidos como fatos e verdade pela reflexão, pela volta do sujeito sobre si mesmo, que percebe a verdade como uma qualidade de sua consciência e não como algo de fora, exterior, que se impōe. Os fatos são simplesmente fatos. Tornam-se verdade na medida em que o sujeito participa, não numa atitude de pura passividade receptiva, obedecendo a uma necessidade interna das coisas, a uma inevitabilidade das estruturas, mas sim pela reflexão da inteligência, distinguindo precisamente dentro do nosso conhecimento, de um lado a nós mesmos, a verdade da consciência humana e doutro lado o mundo de realidade, no qual a verdade da consciência humana marca o próprio homem. Numa palavra, a verdade é realidade humana e não das coisas, dos objetos, dos fatos, dos acontecimentos. Não existem

m. "A consciência moral não é em nós um hábito inato nem a nós imposto por pressões psico-afetivas, sociais ou culturais, de sorte a constituir-se num automatismo cujos efeitos no nosso agir sejam proporcionalmente inversos ao exercício da liberdade. A consciência moral é, ao invés, o próprio agir moral considerado na sua estrutura essencialmente reflexiva. É, pois, um ato, e a sua gênese, bem como a sua atualização permanente no curso da vida moral, confundem-se com o desenvolvimento da personalidade e com a formação progressiva da identidade ética através do crescimento e fortalecimento do organismo das virtudes. Em particular, há uma íntima relação de causa e efeito entre o hábito inato dos primeiros princípios na ordem prática (sinderese), a nitidez e constância do seu influxo no agir proporcionadas pela virtude da prudência (phrónesis), e o pleno exercício da consciência moral e das suas funçōes" (p. 475) ${ }^{18}$. 
fatos brutos para o homem. Eles são sempre interpretados. Isto significa que em cada ato de conhecimento, de verdade, o sujeito se faz presente, com sua historicidade, com seu lugar cultural, social, etc.

$\mathrm{O}$ sujeito compreende-se como o grande intérprete da realidade do mundo, da história, do bem, da verdade, dos valores. Assume a tarefa criativa, original, única de produzir tais interpretações, não as tirando do nada, mas sim em confronto com a objetividade fáctica das coisas, dos eventos. Só há verdade, só há bem, só valor, no momento em que o sujeito participa (p. 60-1) $)^{\mathrm{n}, 19}$.

Essa visão se opõe a uma concepção de consciência a partir de um sujeito que se conforma com a realidade das coisas, dos objetos. Então a consciência moral não irá discernir o que é bem, valor, etc., como realidades exteriores ao próprio sujeito. Não cabe a experiência de um sujeito passivo, acolhedor, mas alguém que reinterpreta toda a realidade.

Nesse sentido, a consciência moral só emerge a partir de uma subjetividade de um sujeito ativo, reflexivo. E ainda, não dá mais, à luz das neurociências, aprofundar a respeito da consciência moral prescindindo do estudo a respeito da influência determinante do funcionamento do cérebro sobre o agir moral de um sujeito. O cérebro não é toda a realidade, mas é uma das realidades fundamentais para se chegar a uma consciência moral que seja ética e responsável. Por mais que entendemos que uma consciência para ser "consciência moral" tem de ser testemunhada pelo aspecto reflexivo e prático que vivencia princípios éticos na busca da verdade, do bem, do valor etc., tudo será também determinado por uma disposição, um condicionamento cerebral. Inclusive, para uma corrente neurocientista, o ser humano tem desenvolvido um instinto moral, uma capacidade que surge de maneira natural sobre o que é moralmente bem ou mal, a ponto de se afirmar que nossos instintos morais são imunes às normas formuladas por governos e religiōes. Algumas vezes, nossas intuições morais coincidem com as normas que emanam da cultura de uma sociedade, em outras vezes, divergem, conflitam $^{20}$. E o que pensar de uma decisão pessoal sabendo que o próprio cérebro é mutação e construção contínua numa realidade auto-organizadora e complexa?

\section{EXIGÊNCIAS PARA A CONSCIÊNCIA MORAL CRISTÃ}

$\mathrm{Na}$ trilha da Tradição, entende-se que a função da consciência está no dinamismo interior que dá sentido e orientação a toda a existência da pessoa humana. A consciência moral aparece como ato que aplica para a vida humana, social exigências fundamentais aos casos, às situaçôes $\mathrm{e}$ ações concretos e determinados ${ }^{7}$. Na perspectiva cristã, a consciência moral não pode deixar de se guiar pela mensagem evangélica.

Para superar uma visão legalista, um subjetivismo moral, um situacionismo moral e um racionalismo exacerbado $^{\circ}$, há que considerar a dimensão interna conjugada

n. O autor trabalha também a consciência a partir do "momento social" (dialético), mostrando que o sujeito é marcado pelas estruturas objetivas, de modo que valor, bem, verdade... são frutos da síntese sujeito e objeto. Por isso se afirma que está na intuição desse momento do social "a percepção aguda de tal relação dialética e da importância das relações sociais de produção e de todas as outras relações humanas na gestação dos valores, verdade, bem. A consciência humana se entende envolvida em três momentos dialéticos, sem possibilidade de separá-los, como entidades por si mesmas. É o mesmo homem que se exterioriza. Tudo que existe no mundo social é criação do homem. Esse universo exteriorizado pelo homem se solidifica, se objetiviza, ganha existência além da consciência e liberdade que o produziu. E começa a exercer sobre esse mesmo sujeito uma ação condicionante, marcante, provocando nele uma internalização de tal realidade. Essa realidade internalizada é, por sua vez, de novo exteriorizada, objetivada, e assim por diante. A consciência dialética do homem consiste precisamente em perceber-se nesse processo dinâmico, contínuo, incessante" (p. 86) ${ }^{19}$.

o. A teologia católica no campo da moral deve muito à Escolástica. Nesse sentido, a teologia tomista ilustra muito bem a posição clássica dentro do catolicismo. Santo Tomás, na sua obra Summa Theologica, na primeira seção da segunda parte (Ia IIae), apresenta a temática da consciência - a visão apresentada vai na perspectiva do racionalismo. A “consciência (conscientia) é definida (Q. 19, Art. 5) como 'a aplicação do conhecimento (scientia) a um ato determinado'. Esta posição está em plena coerência com o que se pode chamar de racionalismo de S. Tomás: a vontade é inseparavelmente apetite sensível e apetite racional, e é humana, somente à medida que está estruturalmente ligada à razão. É a razão que representa a 'forma' do objeto a ser querido, que permite apreender que este é um bem legitimador da vontade ao querer e, portanto, que eleva o apetite espontâneo ou cego a um apetite humanamente (razoavelmente) assumido. (...) A vontade é boa, quando quer um objeto bom, mas esse objeto bom não é apreendido por ela senão à medida que a razão lhe represente como tal (a 'forma'). O mal de uma ação consiste, portanto, ao mesmo tempo no fato de o objeto querido ser em si mesmo mau, mas também, e sobretudo, no fato de a forma sob a qual ele é percebido ser inadequada; desde então se considera aí a chave da posição sobre a consciência equivocada."Na verdade, um objeto ou um ato é bom ou mau senão após a 'forma' que a razão apreende. E um ato de vontade só é humano na medida em que obedece à razão, e, portanto, à medida que se manifesta em conformidade com a 'forma' representada. Em consequência, a consciência é boa na medida estrita em que se adapta às proposições da razão; ela é má se nos desviamos dela. Entretanto, se a razão 'erra', apreendendo mal o objeto a ser querido ou fazendo dele uma falsa representação, ou percebendo mal o elo entre os principais princípios da moral (o que Tomás chama de 'lei natural') e a posição concreta, a consciência se enganará de boa fé e será obrigada a seguir as injunções dessa razão 'errante'. Por conseguinte, uma tal consciência obriga' (p. 203-4)². 
com dimensão externa. Com essa dialética, evita-se fechar num rigorismo moral, vale dizer, no caráter absoluto, por exemplo, das normas morais, dos princípios absolutizados ou das verdades perenes. Exige-se partir, cada vez mais, da convicção pessoal, autônoma e responsável - sabendo dos riscos de uma decisão tomada a partir de uma consciência ingênua, autoritária e desconectada da realidade.

Enfim, a consciência moral, na sua função primária, é dinâmica, interativa e, ao mesmo tempo, orientadora, buscando para o ser humano o que é bom para a humanização e realização da própria vida. Importante lembrar que

a bondade de uma ação não se revela somente em sua fórmula abstrata, por mais objetiva e verdadeira que seja, mas sim no imperativo concreto e pormenorizado de cada situação, do qual também fazem parte outros valores que devem ser reconhecidos e aceitos. E, quando diferentes valores entram em conflito, quando consequências trágicas impedem o cumprimento de uma obrigação, não há nenhuma outra lei, mais particularizada, que imponha com sua força uma das possíveis opções a tomar. Nesse caso, somente a consciência deve e pode discernir o que lhe parece melhor. Se a moralidade radica nesse juízo último, então temos que reconhecer que, em certo sentido, ela é a criadora e artífice do valor ético dessa ação determinada. Seu objetivo não é tanto o cumprimento da norma que tem diante de si, mas muito mais a busca das melhores possibilidades entre as muitas talvez existentes.

Quando não se consegue alcançar o grau de certeza necessária para uma atuação prudente, também não é preciso recorrer aos sistemas morais, com os quais se dá a impressão de que se pretende buscar uma liberdade legal, embora alguns a concedam mais facilmente que outros. No caso, a solução para qualquer dúvida razoável pode ser encontrada por outro caminho, menos complicado e difícil. Se, depois de uma séria reflexão, não se sabe o que escolher nem se consegue eliminar as dúvidas em questão, já se pode ter a suficiente certeza de que, nesses casos, a pessoa está completamente livre, não para prescindir da lei, mas sim para fazer o maior bem possível, para realizar aquilo que julgar melhor e mais importante. O critério último será sempre a máxima autorrealização pessoal. Entretanto... tal posição não tem por que conduzir a um subjetivismo extremo, que deixe espaço para a objetividade. A função intrasubjetiva ocupa lugar primário e constitui um elemento imprescindível na estrutura da obrigação ética; mas esse aspecto, que não pode ser negado, não é tudo na natureza do dever. A consciência transcende o próprio sujeito para colocar-se em relação com a realidade e receber o impacto dos dados procedentes do exterior (p. 335-6) ${ }^{7}$.

Apesar de toda essa sistematização de como funciona ou deveria funcionar a dinâmica da consciência moral, ela não é livre de erro - erro que não pode ser eliminado pelo simples cumprimento da lei, pela análise de todas as circunstâncias que determinam o agir, pela pura obediência às normas morais ou pelo conformismo negligente. A saída mais ética tem sido pela ótica situacionista, a qual aceita a validade e a obrigatoriedade da lei ou das normas morais, mas tudo re-examinado à luz do critério do $S e$ guimento ${ }^{\mathrm{P}}$. A consciência moral cristã tem que orientar a pessoa humana para a prática de Jesus.

O risco é pensar a experiência cristã baseada em certos antropocentrismos que são alicerçados em ideais desproporcionais em nível de exigências para o ser humano, o que acaba prejudicando mais o ser humano do que o ajudando a superar dificuldades diante da própria vida. Há exigências inconcebíveis quando se parte do ser humano concreto, histórico e situado numa realidade complexa. Por exemplo, diante de uma mentalidade heterocentrada, corre-se o risco de discriminar, marginalizar e desrespeitar determinados processos humanos. Todo ser humano apresenta uma herança ontológica que, em muitos aspectos, independe do querer ou não, do optar ou não. Veja o que diz a neurociência a respeito da preferência sexual:

para desespero daqueles que acham que podem 'consertar' as preferências dos filhos (e geralmente para

p. O Seguimento como categoria central da ética cristã, tem que iluminar o agir moral. O Seguimento é o princípio fundante e fundamental de toda ação da experiência cristã - isso significa viver uma adesão a Cristo e à sua proposta do Reino. 
consolo das partes mais interessadas), toda a neurociência aponta para uma determinação biológica (genética e hormonal) da preferência sexual, e precoce, ainda no útero. Que padres e políticos esperneiam à vontade, mas não há qualquer evidência de que o ambiente social influencie a preferência sexual humana. Ou seja: ela vem de fábrica, assim como as características sexuais primárias, ambas determinadas por biologia pura - aliás, pelos mesmos hormônios sexuais produzidos in utero, tanto que, na grande maioria das pessoas, o sexo do corpo e a orientação sexual do cérebro concordam entre si. Não se trata, portanto, de 'opção' sexual, tanto que tentativas sociais de convencer humanos ou outros animais a mudar de preferência ou identidade sexual nunca deram muito certo; até hoje, a única coisa que chegou perto de fazer machos ou fêmeas buscarem contato heteroou homossexual sob encomenda foi a manipulação hormonal em ratos. O que ocorre na adolescência é a expressão da preferência sexual que se formou durante a gestação (p. 28-9) q,21.

Antes das normas, das leis, das culturas, das morais... está a vida. A vida com sua história e suas circunstâncias!
Por fim, refletir sobre como tratar a consciência moral cristã a partir dos dados que fornecem o mundo da neurociência, a qual deve ser também iluminada pela teoria do holomovimento, nos leva a novos compromissos na área do conhecer e das práticas concretas em relação aos seres humanos. A humildade e a tolerância, a sensibilidade e a caridade, a sabedoria e a ciência, o diálogo e a ética, a atualização e a responsabilidade, devem fazer parte de toda ação que provém de uma consciência moral cristã. Os pré-juízos ou pré-julgamentos podem condenar seres humanos a uma vida injusta, sofrida ou infeliz. Há que compreender que, em muitas situações existenciais, a pessoa humana não tem condição de responder exigências enraizadas em racionalismos, idealismos e perfeccionismos. E ainda: em nome desses "grandes" referenciais, temse subordinado a consciência a uma experiência de autoritarismo, legalismo, sacrifícios injustificáveis. Antes das determinações dogmáticas e utópicas, dos grandes projetos institucionais e societários, está a vida humana (singular e complexa, histórica e auto-organizacional), a partir da sua consciência moral, buscando lutar por uma sobrevivência mais humana, livre, bonita e feliz! E é para isso que deverá servir a consciência moral cristã.

\section{REFERÊNCIAS}

1. Majorano S. A consciência. Uma visão cristã. Aparecida (SP): Santuário; 2000. v. 4.

2. Valadier P. Elogio da consciência. São Leopoldo (RS): Unisinos; 2000.

3. Editorial. Igreja e Consciência. Perspectiva Teológica. 2012;44(124):345-52.

4. Azpitarte EL. Conflitos e magistério da Igreja. Perspectiva Teológica. 2012;44(124):353-72.

5. Vidal M. Para conhecer a ética cristã. São Paulo: Edições Paulinas; 1993.

6. Moser A, Leers B. Teologia moral: impasses e alternativas. Petrópolis (RJ): Vozes; 1987.

7. Azpitarte EL, Orduña RR, Bartrés GM. A práxis cristã. Moral fundamental I. São Paulo: Ediçōes Paulinas; 1983. v. 1.

8. Mora F. El científico curioso: la ciencia del cerebro en el día a día. Madrid: Ediciones Planeta; 2008.

9. Damásio AR. E o cérebro criou o homem. São Paulo: Companhia das Letras; 2011.

10. Damásio AR. Em busca de Espinosa: prazer e dor na ciência dos sentimentos. São Paulo: Companhia das Letras; 2004.

11. Varela F. Cerebro y conciencia. In: Mora F, coordinador. Esplendores y miserias del cerebro. Fundación Santander Central Hispano; 2004.

12. Damásio AR. O erro de Descartes. Emoção, razão e o cérebro humano. São Paulo: Companhia das Letras; 1996.

13. Damásio AR. O mistério da consciência. Do corpo e das emoçôes ao conhecimento de si. São Paulo: Companhia das Letras; 2000.

q. Afirma a neurocientista: “Importante mesmo é que a atração pelo mesmo sexo e a sensação de ter nascido 'do sexo errado’ não podem mais ser consideradas 'aberraçôes psicológicas' ou frutos de criação 'errada' pela família, escola ou sociedade em geral; são biologia pura. E, como toda biologia, essa que determina a identidade e a preferência sexual também está sujeita a variações e influências químicas e genéticas nem sempre bem compreendidas (para um biólogo, aliás, surpresa seria se todos fossem iguais!). A maior lição desta em particular parte da neurociência da adolescência é que não são os hormônios da puberdade nem a genitália que definem a identidade sexual ou a preferência por parceiros, parceiras ou ambos - ou a adolescência não traria surpresa para ninguém! Reveladas quando do cérebro adolescente, sensibilizado pelos hormônios sexuais produzidos sob seu controle, expressa o caminho que tomou ainda na gestação, identidade e preferência sexual não se escolhem; descobrem-se" (p. 56, grifo nosso) ${ }^{21}$. 
Revista B10\&THIKOS - Centro Universitário São Camilo - 2014;8(1):31-45

14. Capra F. As conexões ocultas. Ciência para uma vida sustentável. São Paulo: Cultrix; 2002.

15. Di Biase F, Schweitzer A, Rocha MS. Informação, auto-organização e consciência. In: Di Biase F, Amoroso R, organizadores. A revolução da consciência. Novas descobertas sobre a mente no século XXI. Petrópolis (RJ): Vozes; 2004. p. 247-68.

16. Gazzaniga MS. El cerebro ético. Barcelona: Paidós Ibérica SA; 2006.

17. Wilson JQ. The moral sense. New York: Free Press; 1993.

18. Lima Vaz HC. Crise e verdade da consciência moral. Síntese Nova Fase. 1998;25(83):461-76.

19. Libânio JB. Formação da consciência crítica. Subsídios filosófico-culturais. Petrópolis (RJ): Vozes; 1982.

20. Hauser MD. Moral minds. How nature designed our universal sense of right and wrong. Nova York: HarperCollins Publishers; 2006.

21. Herculano-Houzel SC. Cérebro em transformação. Rio de Janeiro: Objetiva; 2005. 